\title{
SYNTHESIS, CHARACTERIZATION AND DYE REMOVAL PROPERTIES OF CELLULOSE NANOCRYSTALS EMBEDDED NATURAL RUBBER LATEX COMPOSITE
}

\author{
AISWARYA R. NAIR, SREEDHA SAMBHUDEVAN and BALAKRISHNAN SHANKAR* \\ Department of Chemistry, Amrita Vishwa Vidyapeetham, Amritapuri, India \\ "Department of Mechanical Engineering, Amrita Vishwa Vidyapeetham, Amritapuri, India \\ $\square$ Corresponding author: Sreedha Sambhudevan, sreedha@am.amrita.edu
}

Received February 5, 2018

Cellulose nanocrystals (CNCs) were prepared from bleached wood pulp by the acid hydrolysis method. CNCs were characterized by Fourier Transform Infrared Spectroscopy (FTIR) and X-Ray Diffraction (XRD). Natural rubber latex was oxidised using potassium permanganate. The oxidation of latex was confirmed using FTIR and UV-Visible Spectroscopy. Natural rubber latex composites were prepared using the as-prepared CNCs in two different weight percentages. Mechanical studies and microscopy analysis proved that the incorporation of CNCs into NR latex improved all the properties. Due to the presence of surface hydroxyl groups of CNCs, which can be exchanged with almost any contaminant ions present in water, the developed materials can be utilized for water purification. The composites effectively removed $92 \%, 79 \%$ and $67 \%$, respectively, of basic dyes such as Victoria blue BO, Methyl violet $10 \mathrm{~B}$ and Holacryl pink FG. The dye removal can be explained by the electrostatic attraction between the negatively charged CNCs and the positively charged dyes.

Keywords: cellulose nanocrystals, natural rubber latex, nanocomposites, dye removal

\section{INTRODUCTION}

Even though water is a renewable source, its quantity has not changed globally for the past 2000 years. Moreover, only three percent of the available water is fresh and one third of it is inaccessible. To make matters worse, the water available is often contaminated with effluents from industries, agriculture and households, especially, from dyes and pigment industries. ${ }^{1}$ Dyes are very important chemicals and because of their complex structure, they are nonbiodegradable, and hence their removal from water is not an easy task. ${ }^{2}$

Purifying water using today's technology is performed by techniques such as osmosis/reverse osmosis, various filtration processes, UV sterilization, ozonolysis, distillation etc. Most of them involve the use of non-biologic origin, nonrecyclable and harmful to the environment materials, as well as have high energy requirements. Thus, it is undoubtful that there is a high need to research into innovative measures to clean water at lesser costs, using reduced energy, while reducing the harsh impacts on the environment. $^{3}$
Polymer nanocomposites are a new range of materials that are promising for water purifycation. Nanotechnology is the field where almost all branches of science are incorporated, exploiting the characteristic properties of materials in the nanoscale range. A major field of application of nanoparticles are in the manufacture of composites, which have proven to be manyfold superior to the conventional macro/micro-polymer composites. ${ }^{4}$ The selection of a suitable filler and matrix phase plays a vital role in the effectiveness of the end use of the developed composites. ${ }^{5}$ Composites containing biological polymers, instead of synthetic polymers, are more eco-friendly. However, many of the already developed biopolymers lack a variety of desirable properties exhibited by synthetic polymers. Therefore, their reinforcement and the improvement of their properties are much needed and always an area of interest for scientists. Recent studies have proven that certain commonly used nanoparticles (NPs), such as carbon nanotubes $(\mathrm{CNTs}), \mathrm{TiO}_{2}$, etc., can be 
toxic and need to be substituted with non-toxic ones. Bionanoparticles (BNPs) can be used to tackle this problem. BNPs are simply nanoparticles of biological origin and are potentially less toxic than their precursors. By the combination of a biopolymer as matrix and BNPs as fillers, one can develop a desired bionanocomposite (BNC). ${ }^{7}$ BNCs are a new type of nano-sized materials, which provide a great array of benefits, such as non-toxicity, biocompatibility, availability of raw materials, ease of synthesis, flexibility and almost zeropollution.

Cellulose nanocrystals (CNCs) are needle-type cellulose units with one dimension in the nanorange, with highly crystalline nature. These nanomaterials of biological origin present interest due to their exclusive structural properties and striking physicochemical peculiarities, such as biocompatibility, biodegradability, renewability, low density, adaptable surface chemistry, optical transparency and improved mechanical properties. ${ }^{8}$ They are perfect candidates for a wide variety of applications, such as biomedical, pharmaceuticals, electronics, barrier films, nanocomposites, membranes, super-capacitors, etc. ${ }^{9-11}$ In addition, the excellent properties of $\mathrm{CNCs}$ make them an excellent candidate for water purification. ${ }^{12-14}$ The hydrophilic nature of cellulosic nanostructures are highly appreciated in reducing bio- and organic fouling. ${ }^{15-16}$ Literature review have shown that incorporating organic functional groups into nanocellulose is highly useful in selective uptake of contaminants and hence water purification. ${ }^{17-19}$ Researchers are also developing some novel methods of utilising cellulose in different ways. The synthesis of porous carbon from cellulose for dye absorption, cellulose/chitosan composite films for anionic dye removal and utilization of TEMPO-oxidised cellulosic fractions for dye removal are some of the recent trends in this area. ${ }^{20-22}$

In the present work, $\mathrm{CNCs}$ were prepared from wood pulp and natural rubber latex was used as matrix material to synthesize $\mathrm{CNC} /$ natural rubber nanocomposites, which can be used as a promising material for water purification.

\section{EXPERIMENTAL}

\section{Materials and methods}

Bleached wood pulp was received from Hindustan Newsprint Ltd., Velloor, Kerala. Laboratory grade formic acid and $\mathrm{HCl}$, as well as natural rubber (NR) latex, with dry rubber content of $60 \%$, was purchased from Sacharia Latex Exporters, Kottayam, Kerala. $\mathrm{KMnO}_{4}$ crystals of laboratory grade were also used.

\section{CNC preparation}

Two grams of bleached chemical pulp was added to a mixture of $90 \% \mathrm{HCOOH}$ and $10 \% \mathrm{HCl}$, and then vigorously agitated to obtain a pulp-like slurry. Later, the reaction was carried out in a round bottom flask $(250 \mathrm{~mL}) \mathrm{kept}$ in an oil bath at $95{ }^{\circ} \mathrm{C}$ for $30 \mathrm{~min}$, with magnetic stirring at $900 \mathrm{rpm}$. On finishing the reaction, the flask was instantly cooled to room temperature, using water, and centrifuged until the mixture yielded a clear supernatant liquid. The solid residue was collected and dissolved in $100 \mathrm{~mL}$ distilled water, which was freeze-dried on a Freezone 2.5 Labconco Freeze Dry System.

\section{NRL oxidation}

A $\mathrm{KMnO}_{4}$ solution was used to oxidise the NR latex. An aqueous solution of $0.125 \mathrm{~mol} \mathrm{~L}^{-1} \mathrm{KMnO}_{4}$ was prepared and diluted to 0.0125 and $0.00125 \mathrm{~mol}$ $\mathrm{L}^{-1}$, and then added dropwise to the NR latex suspension under stirring, so as to achieve the oxidation of the double bonds present in the isoprene monomer. The typical colour variation of the solution from pink to brown and the formation of solid $\mathrm{MnO}_{2}$ indicated that the oxidation process was over.

\section{Preparation of composite film}

An aqueous suspension of CNCs was made neutral and the NR latex was added in different quantities at normal temperature, and was uniformly mixed to get a good dispersion. The mixture was kept in vacuum and agitated on a Rotavapor for $10 \mathrm{~min}$, to degas the mixture and to avoid the development of permanent foams in the course of water evaporation. Thin films of identical thickness were attained by casting on a glass mould and was evaporated at $40{ }^{\circ} \mathrm{C}$ in an oven for 4-6 hours and then heated at $60{ }^{\circ} \mathrm{C}$ for 2 days. The resultant films were stored at room temperature in a desiccator with $\mathrm{CaCl}_{2}$. The films containing $2 \% \mathrm{CNC}$ and $4 \%$ CNC were prepared similarly and then characterised with regard to their properties.

\section{Fourier Transform Infrared Spectroscopy (FTIR)}

FTIR was performed using a Perkin Elmer Spectrum Two-FTIR spectrophotometer in the range of $4000-400 \mathrm{~cm}^{-1}$. The particles were powdered well and embedded in $\mathrm{KBr}$ crystals before taking the spectra. A pressure of 65-105 $\mathrm{MPa}$ was applied to get a transparent disc. The FTIR spectra of latex and oxidized latex were also taken using the Attenuated Total Reflection (ATR) method.

\section{X-Ray Diffraction (XRD)}

The XRD patterns of the samples were taken at room temperature on a Bruker AXS D8 Advance diffractometer, using a $\mathrm{Ni}$ filter, and equipped with a $\mathrm{Cu}$ X-ray source, at a wavelength of $1.5406 \AA$, 
generator voltage of $60 \mathrm{kV}$ and generator current of 40 $\mathrm{mA}$. The samples were scanned at a step size of 0.020 $2 \theta$ and step time 32.8 seconds.

\section{Scanning Electron Microscopy (SEM)}

Surface morphology was studied by means of a FEI Quanta 200 scanning electron microscope, using $5 \mathrm{keV}$ secondary electrons. With liquid nitrogen, the samples were cryogenically fractured, followed by gold plating to minimize surface charging.

\section{UV-Visible Spectroscopy}

UV-visible absorption spectroscopy was employed to study the optical properties of the prepared samples, using a Perkin Elmer LAMBDA 265 UV-Vis spectrophotometer in the range of $300-700 \mathrm{~nm}$.

\section{Mechanical properties}

Tensile strength was measured according to ASTM method D412-98 and tear strength - according to ASTM method D624-98, on an Instron 4411 (England) Universal Testing Machine (UTM) at a cross head speed of $500 \mathrm{~mm} / \mathrm{min}$ and $100 \mathrm{~mm} / \mathrm{min}$, respectively. Tensile tests were done using dump-bell shaped samples and tear tests were done using crescent shaped specimens.

\section{RESULTS AND DISCUSSION FTIR analysis}

Figure 1 shows the FTIR spectrum of CNCs, while Figure 2 presents an enlarged view of the spectrum. The spectrum exhibits a band at 3342 $\mathrm{cm}^{-1}$ that corresponds to the free $\mathrm{O}-\mathrm{H}$ stretching vibration of the $\mathrm{OH}$ groups in cellulose. The spectrum indicates the characteristic $\mathrm{C}-\mathrm{H}$ stretching vibration around $2905 \mathrm{~cm}^{-1}$. The vibration peak detected at $1507 \mathrm{~cm}^{-1}$ is due to the $\mathrm{CH}_{2}$ scissoring motion in cellulose, that at 1462 $\mathrm{cm}^{-1}$ is due to $\mathrm{C}-\mathrm{H}$ bending, that at $1430 \mathrm{~cm}^{-1}$ is due to in-plane $\mathrm{O}-\mathrm{H}$ bending, the peak at 1322 $\mathrm{cm}^{-1}$ is due to $\mathrm{CH}_{2}$ wagging, and that at $1035 \mathrm{~cm}^{-1}$ is related to $\mathrm{C}-\mathrm{O}-\mathrm{C}$ stretching vibration in the pyranose ring. A close analysis reveals a peak in the region between $902-893 \mathrm{~cm}^{-1}$, which is associated with the cellulosic $\beta$-glycosidic linkages. ${ }^{23}$ The peak at $1160 \mathrm{~cm}^{-1}$ is due to $\mathrm{C}-\mathrm{C}$ ring stretching, and that at $1110 \mathrm{~cm}^{-1}$ is due to the $\mathrm{C}-\mathrm{O}-\mathrm{C}$ glycosidic ether band. The absorbance peaks observed in the spectra of cellulose fibres, in the region of $1645 \mathrm{~cm}^{-1}$, were attributed to the $\mathrm{O}-\mathrm{H}$ bending of the adsorbed water. The somewhat higher moisture content is due to the absorption of water in the void spaces formed by the removal of hemicellulose and lignin. Lastly, the peak found in the spectra between 1040 and $1109 \mathrm{~cm}^{-1}$ is attributed to the $\mathrm{C}-\mathrm{O}-\mathrm{C}$ pyranose ring stretching vibration. ${ }^{24}$

Figures 3 and 4 illustrate the FTIR spectra of NR latex and oxidised NR latex, respectively. The absorption at $831 \mathrm{~cm}^{-1}$ indicates out-of-plane $=\mathrm{CH}$ bending of cis-1,4- . The corresponding peak in oxidized NRL proves the effective oxidation of the double bonds. A closer examination of the infrared spectra discloses the absorbance band at $1219 \mathrm{~cm}^{-1}$, corresponding to O-P-O asymmetric stretching of phospholipids, signifying the presence of related phospholipids at the rubber chain. The absorption bands at $1367 \mathrm{~cm}^{-1}$ and $1447 \mathrm{~cm}^{-1}$ (C-H bending) are features of $\mathrm{CH}_{2}$ distortion. The absorption band at $1645 \mathrm{~cm}^{-1}$ resembles $\mathrm{C}=\mathrm{C}$ stretching in cis-1,4-polyisoprene. This peak is also found in the spectrum of oxidised NRL, at $1644 \mathrm{~cm}^{-1}$, with a lower intensity, due to the oxidation of surface molecules only. This property is highly appreciated since the final composite will have the required characteristics of NR, keeping in mind that the extent of oxidation can be varied as per the requirements. The $\mathrm{CH}_{2}$ symmetric stretching vibrations are observed in the region of $2855 \mathrm{~cm}^{-1}$. The $\mathrm{CH}_{3}$ asymmetric stretching in the spectrum of NRL is observed at $2955 \mathrm{~cm}^{-1}$. In addition, the spectrum also shows a broad peak at around $3200-3500 \mathrm{~cm}^{-1}$. This absorption band might be related to the presence of a hydroxyl group, since latex is an emulsion of polymer microparticles in an aqueous medium. The peak at $1744 \mathrm{~cm}^{-1}$ present in the NR sample is related to the molecules available on the outer part of latex particles. There is a slow decrease in the intensity of this peak as the oxidation level rises, confirming that these surface molecules are oxidized during the reaction.

\section{XRD analysis}

X-ray diffraction patterns of $\mathrm{CNCs}$ are shown in Figure 5. Particle size was calculated using Scherer's equation, $D=k \lambda B \cos \theta$, where $D$ is the particle size, $K$ is a constant called dimensionless shape factor, $\lambda$ is the wavelength of the $\mathrm{X}$-ray used, $B$ is line broadening at half the maximum intensity and $\theta$ is the Bragg angle. The calculated values for the particle size are listed in Table 1 . 
AISWARYA R. NAIR et al.

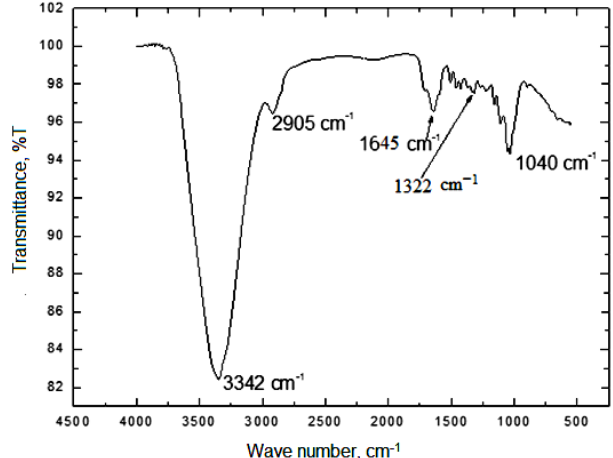

Figure 1: FTIR spectrum of CNCs

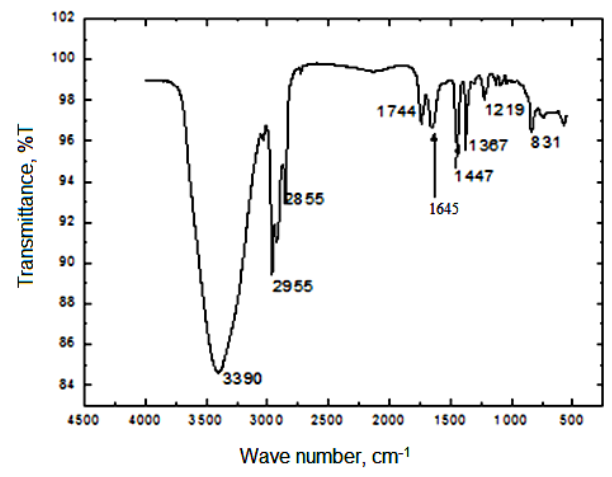

Figure 3: FTIR spectrum of NR latex

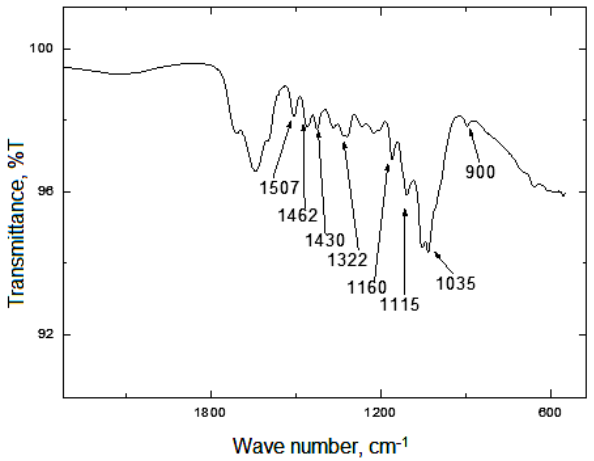

Figure 2: Enlarged FTIR spectrum of CNCs

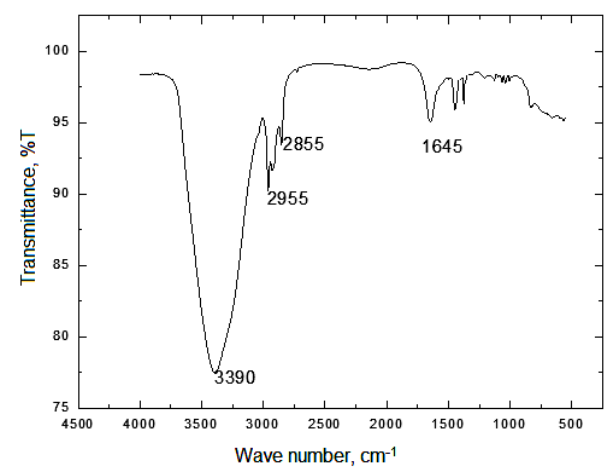

Figure 4: FTIR spectrum of oxidised NR latex

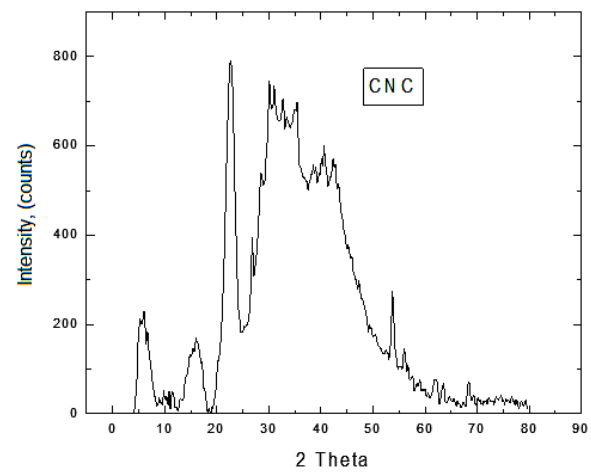

Figure 5: XRD pattern of CNCs

Table 1

Calculated particle size values of $\mathrm{CNCs}$

\begin{tabular}{cccc}
\hline $2 \theta$ & FWHM & $\lambda$ & $\mathrm{D}$ \\
\hline 53.714 & 0.391 & 0.15406 & 23.1 \\
26.8 & 0.282 & 0.15406 & 29.5 \\
22.59 & 1.805 & 0.15406 & 24.5 \\
\hline
\end{tabular}



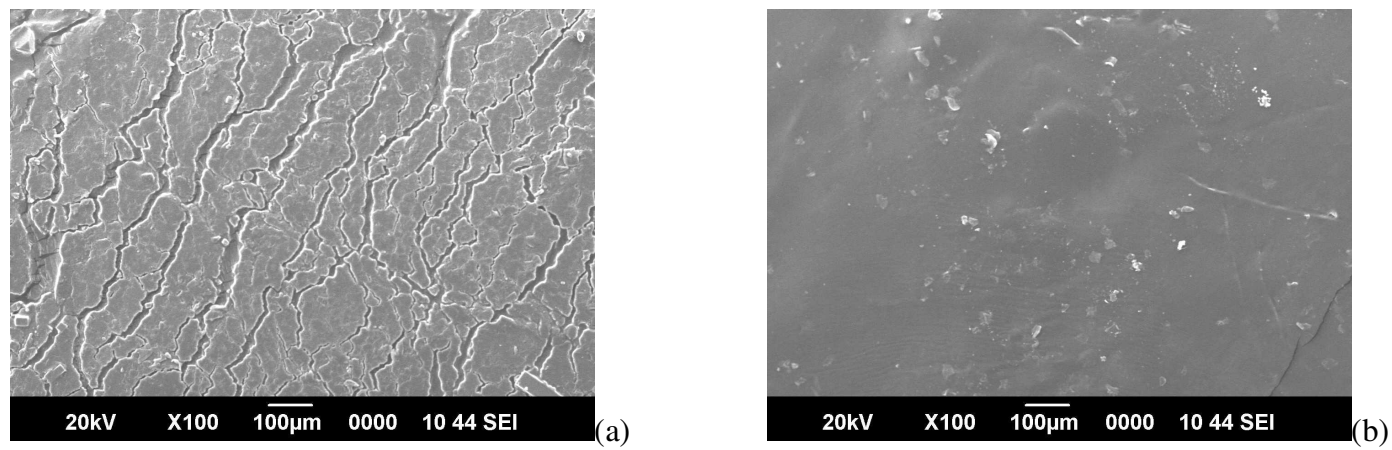

Figure 6: SEM micrographs of (a) latex film and (b) composite film

Average particle size was calculated using Scherer's equation and was found to be $25.7 \mathrm{~nm}$. The nanometre-sized crystalline particles proved that the hydrolysis was effective and the amorphous region of cellulose was removed successfully.

\section{SEM}

From the SEM micrographs presented in Figure 6, it is clear that the introduction of CNCs into rubber latex increases the homogeneity of latex particles in the composite. A homogeneous distribution of $\mathrm{CNC}$ particles in the latex can be observed from the SEM images, which is essential for the optimum properties of latex composites. The increase in homogeneity is also supported by the studies of the mechanical properties of the nanocomposites.

\section{UV-Vis analysis}

New $-\mathrm{OH}$ groups are introduced in the NR matrix through permanganate oxidation. It is assumed that 1 mole of $\mathrm{KMnO}_{4}$ can produce 2 moles of new $-\mathrm{OH}$ groups via the oxidation reaction of the polymer, the concentration of the oxidant was varied to obtain different ratios of $\mathrm{OH}$ and $\mathrm{CNC}$. The newly introduced $-\mathrm{OH}$ groups facilitate the CNC-NRL interaction, owing to probable hydrogen bonding. In the presence of a base, the reduction of manganese (VII) ions to manganese (VI) ions takes place, which resulted in brown solid manganese (IV) oxide.

Reaction I: $\mathrm{MnO}_{4}^{-}+\mathrm{H}_{2} \mathrm{O}+\mathrm{e}^{-} \longrightarrow$ $\mathrm{MnO}_{4}{ }^{2-}($ at $\mathrm{pH}>7)$

Reaction II: $\mathrm{MnO}_{4}{ }^{2-}+\mathrm{H}_{2} \mathrm{O}+2 \mathrm{e}^{-} \longrightarrow$
$\mathrm{MnO}^{2}+4 \mathrm{OH}^{-}$

Manganese (VII) has a typical absorption band in the UV region, with the maximum absorbance at $525 \mathrm{~nm}$, which was utilized to confirm the oxidation reaction. When the oxidation reaction takes place, the manganese (VII) available in the suspension gradually turns to manganese (IV) and the typical purple colour diminishes. When an excess of $\mathrm{MnO}_{4}{ }^{-}$exists in the suspension, the purple colour perseveres and it reveals the end of the reaction, owing to the lack of availability of double bonds in the polymer. Figures 7 and 8 show the UV-Vis spectra of the NRL suspension after the oxidation reaction and the $\mathrm{KMnO}_{4}$ solution used for the oxidation, respectively. The presence of the peak at $525 \mathrm{~nm}$ is noted in the spectrum of the $\mathrm{KMnO}_{4}$ solution, but not in that of the NRL suspension, confirming the complete usage of the reagent.

\section{Measurements of mechanical properties}

Tensile property tests were performed on the films formed from NRL, and NRL with $2 \% \mathrm{CNCs}$ and with $4 \%$ CNCs. The results are shown in Table 2. Positive results were achieved, as expected. Tensile strength and tensile modulus were noted to increase with the increase in CNC concentration, while the elongation at break decreases with the increase in CNC content. The $\mathrm{OH}$ groups in NRL chains favour the interaction of the matrix with CNCs, which helps in the transfer of stress, which could be the reason for the observed increase in mechanical properties of the materials. 


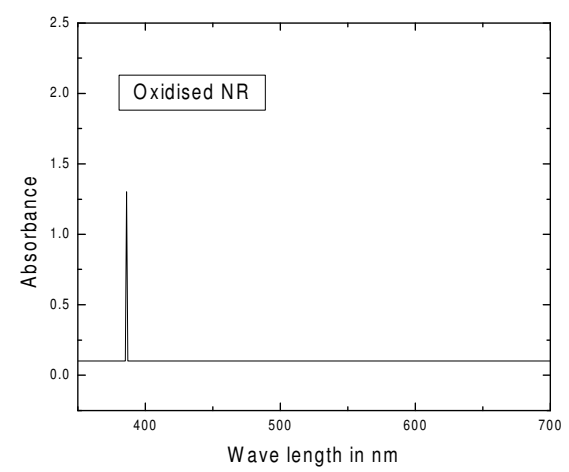

Figure 7: UV-visible spectrum of oxidised NR latex

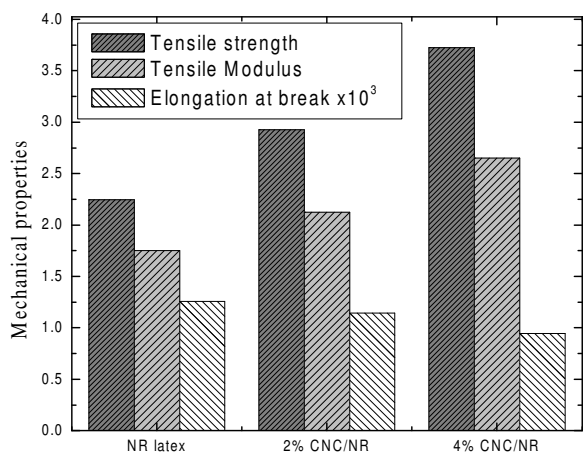

Figure 9: Graphical representation of mechanical properties of NRL, $2 \% \mathrm{CNC} / \mathrm{NR}$ and $4 \% \mathrm{CNC} / \mathrm{NR}$

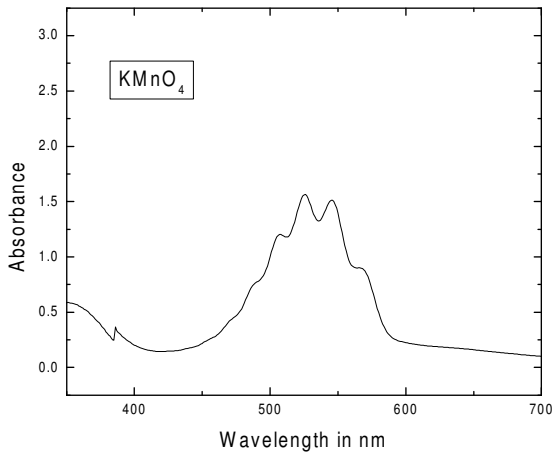

Figure 8: UV-visible spectrum of $\mathrm{KMnO}_{4}$

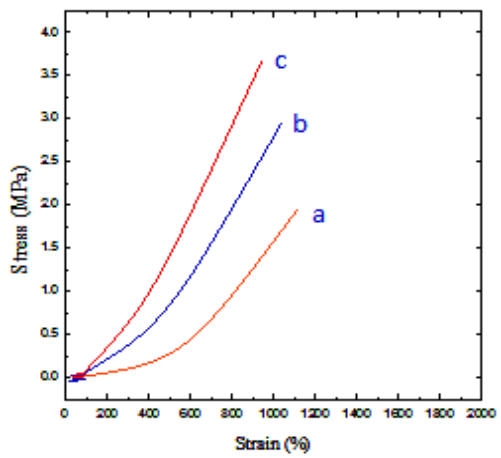

Figure 10: Stress-strain curves of (a) NRL, (b) $2 \% \mathrm{CNC} / \mathrm{NR}$ and (c) $4 \% \mathrm{CNC} / \mathrm{NR}$

Table 2

Mechanical properties of NRL, $2 \%$ CNC in NRL and $4 \%$ CNC in NRL

\begin{tabular}{lccc}
\hline Sample & $\begin{array}{c}\text { Tensile strength } \\
(\mathrm{M} \mathrm{Pa})\end{array}$ & $\begin{array}{c}\text { Tensile modulus } \\
(\mathrm{M} \mathrm{Pa})\end{array}$ & $\begin{array}{c}\text { Elongation at break } \\
(\%)\end{array}$ \\
\hline NR latex & 2.2468 & 1.7525 & 1258.56 \\
$2 \%$ CNC in NR & 2.9263 & 2.1248 & 1145.23 \\
$4 \%$ CNC in NR & 3.7246 & 2.6523 & 946.53 \\
\hline
\end{tabular}

\section{Estimation of dye removal ability}

UV-visible spectroscopy was used to analyse the untreated and treated model wastewater. The percentage removal was determined using the formula:

$A_{0}-\frac{A_{t}}{A_{0}} \times 100$

where $A_{0}$ is the absorbance of the dye solution filtered with the latex membrane and $A_{t}$ is the absorbance of the dye solution filtered with the composite membrane.

The absorbance of each dye was noted at their $\lambda_{\max }$, using the UV-vis spectrophotometer. The optical absorbance of the dyes Victoria blue BO, Methyl violet 10B and Holacryl pink FG was observed at 583,529 and $618 \mathrm{~nm}$, respectively, by
UV-Vis spectroscopy to determine the percentage removal of the dyes. A stock solution of model wastewater was prepared by adding dyes (10 $\mathrm{mg} / \mathrm{L}$ ) in deionized water to determine the adsorption of the dyes onto the uncross-linked and cross-linked membranes. The composite membranes, cut into pieces of $25 \times 15 \mathrm{~mm}$, were incubated for $24 \mathrm{~h}$ in the model wastewater solution of $\mathrm{pH} 5$, at room temperature $\left(25 \pm 2{ }^{\circ} \mathrm{C}\right)$, under stirring. The latex membrane was chosen as the control for measuring the adsorption of the dyes onto the composite membranes by the method stated above. The experiments were conducted in the absence of light to avoid photodepletion. 
Cellulose

Table 3

Effect of type of dye on the percentage removal of dyes

\begin{tabular}{lc}
\hline Type of dye & Percentage removal of dyes \\
\hline Victoria blue BO & $92 \pm 2.1$ \\
Methyl violet 10B & $79 \pm 1.9$ \\
Holacryl pink FG & $67 \pm 1.2$ \\
\hline
\end{tabular}

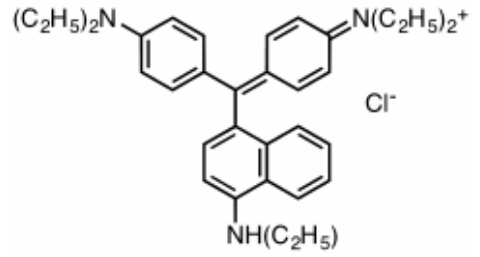

Figure 11: Structure of Victoria blue BO

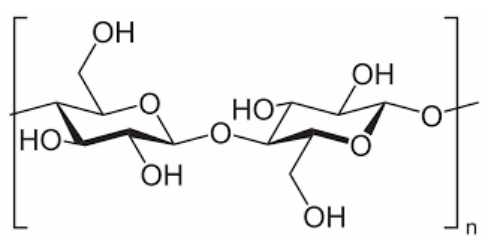

Figure 12: Structure of cellulose

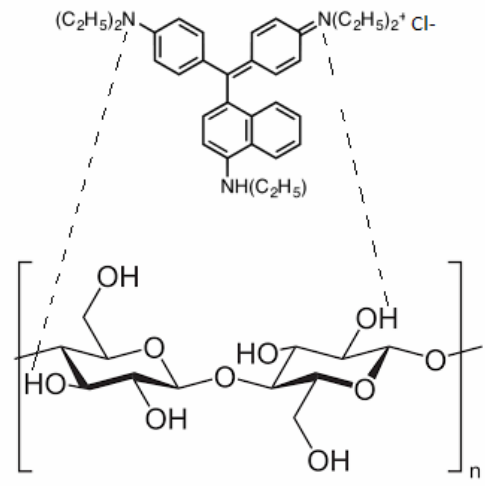

Figure 13: Binding mechanism of the dye to CNCs through hydrogen bonding

\section{CONCLUSION}

Cellulose nanocrystals were prepared successfully from bleached wood pulp and were characterised using FTIR and XRD. Natural rubber latex was oxidised using $\mathrm{KMnO}_{4}$. The oxidation facilitated the interaction between CNCs and NRL. Successful casting of CNC embedded NRL composite films, with $2 \%$ and $4 \%$ $\mathrm{CNC}$ concentration, was achieved and supported using FTIR, XRD, SEM and UV-Vis analysis techniques, as well as by assessing the mechanical properties of the materials. The obtained films showed enhanced mechanical properties. It is expected that the developed CNC embedded NRL films can be used as an economic upgrade in the water purification industry. Due to the abundant surface hydroxyl groups of CNCs, which can be exchanged with almost any contaminant ions present in wastewater, such materials can serve as filtration membranes in the water purification industry. Moreover, the enhanced mechanical properties of the novel composite support their proposed application in the water purification industry.

\section{REFERENCES}

1 J. Bandyopadhyay, Int. J. Water Resour. Dev., 11, 411

(1995), https://doi.org/10.1080/07900629550042119

2 A. K. Biswas and C. Tortajada, Int. J. Water Resour. Dev., $\quad 2, \quad 129 \quad$ (2010), https://doi.org/10.1080/07900627.2010.488853

3 C. P. Leo, M. Z. Yahya, S. N. M. Kamal, A. L. Ahmad and A. W. Mohammad, Water Sci. Technol., 4, 831 (2013), https://doi.org/10.2166/wst.2012.625

4 D. R. Paul and L. M. Robeson, Polymer, 15, 3187 (2008), https://doi.org/10.1016/j.polymer.2008.04.017

5 R. Lin, B. V. Hernandez, L. Ge and Z. Zhu, J. Mater. Chem., 2, 293 (2018), DOI: 10.1039/C7TA07294E

6 W. Wang, A. Sedykh, H. Sun, L. Zhao, D. P. Russo et al., ACS Nano, 12, $12641 \quad$ (2017), https://doi.org/10.1021/acsnano.7b07093

X. Q. Zhang, X. Xu, N. Bertrand, E. Pridgen, A. Swami et al., Adv. Drug Deliv. Rev., 13, 1363 (2012), https://doi.org/10.1016/j.addr.2012.08.005

8 D. Trache, M. H. Hussin, M. K. M. Haafiz and V. K. Thakur, Nanoscale, 5, 1763 (2017), DOI: 10.1039/C6NR09494E 
AISWARYA R. NAIR et al.

9 R. Singla, A. Guliani, A. Kumari and S. Yadav, Nanocellulose and Nanocomposites, 5, 103 (2016).

10 K. J. De France, T. Hoare and E. D. Cranston, Chem. Mater., 1, $4609 \quad$ (2017), https://doi.org/10.1021/acs.chemmater.7b00531

11 X. Zhuo, C. Liu, R. Pan, X. Dong and Y. Li, ACS Sustain. Chem. Eng., 5, 4414 (2017),

https://doi.org/10.1021/acssuschemeng.7b00478

12 P. Liu, K. Oksman and A. P. Mathew, J. Colloid Interface Sci., $\mathbf{4 6 4}, \quad 175 \quad$ (2016), https://doi.org/10.1016/j.jcis.2015.11.033

13 H. Sehaqui, A. Mautner, U. P. de Larraya, N. Pfenninger, P. Tingaut et al., Carbohyd. Polym., 135, 334 (2016), DOI: 10.1016/j.carbpol.2015.08.091

14 L. Jin, W. Li, Q. Xu and Q. Sun, Cellulose, 4, 2443 (2015), DOI 10.1007/s10570-015-0649-4

15 V. K. Thakur and S. I. Voicu, Carbohyd. Polym., 146, 148

(2016), https://doi.org/10.1016/j.carbpol.2016.03.030

16 H. Voisin, L. Bergström, P. Liu and A. P. Mathew, $\begin{array}{llll}\text { Nanomaterials, } & \mathbf{7}, & 57 & \text { (2017), }\end{array}$ https://doi.org/10.3390/nano7030057

17 C. Zhu, I. Dobryden, J. Rydén, S. Öberg, A. Holmgren et al., Langmuir, 45, 12390 (2015), https://doi.org/10.1021/acs.langmuir.5b03228
18 R. Wang, S. Guan, A. Sato, X. Wang, Z. Wang et al., J. Membrane Sci., 446, 376 (2013), doi: 10.1016/j.memsci.2013.06.020

19 B. Chen, Q. Zheng, J. Zhu, J. Li, Z. Cai et al., RSC $A d v .$, 99, 96518 (2016), doi: 10.1039/C6RA19280G

20 Y. Hao, Z. Wang, Z. Wang and Y. He, Ecotoxicol. Environ. $\quad S a f ., \quad \mathbf{1 6 8}, \quad 298 \quad$ (2019), https://doi.org/10.1016/j.ecoenv.2018.10.076

21 X. Zheng, X. Li, J. Li, L. Wang, W. Jin et al., Int. J. Biol. Macromol., 107, $283 \quad$ (2018), https://doi.org/10.1016/j.ijbiomac.2017.08.169

22 G. Biliuta, D. Suteu, T. Malutan, A.-I. Chirculescu, I. Nica et al., Cellulose Chem. Technol., 52, 609 (2018),

http://www.cellulosechemtechnol.ro/pdf/CCT78(2018)/p.609-618.pdf

23 L. A. de S. Costa, A. F. Fonseca, F. V. Pereira and J. I. Druzian, Cellulose Chem. Technol., 2, 127 (2015), http://www.cellulosechemtechnol.ro/pdf/CCT2(2015)/ p.127-133.pdf

24 M. Rahimi Kord Sofla, R. J. Brown, T. Tsuzuki and T. J. Rainey, Adv. Nat. Sci: Nanosci. Nanotechnol., 3, 1 (2016), DOI: 10.1088/2043-6262/7/3/035004 